radiation) and the conclusion of Stewart et al. ${ }^{7}$ amounts to a factor of between about 2 and 10, say. In view of the many uncertainties this is not altogether unreasonable; nevertheless considerations (i) to (iv) indicate that the discrepancy could be a real one.

$$
\begin{gathered}
\text { Medical Research Council, } \\
\text { Environmental Radiation Research Unit, } \\
\text { Department of Medical Physics, } \\
\text { University of Leeds, } \\
\text { General Infirmary, Leeds. }
\end{gathered}
$$$$
\text { P. R. J. BURCH. }
$$

\section{CARE OF THE ELDERLY DISTURBED PATIENT}

SIR,-I should like to support the letter by Dr. Horace Joules (Feb. 9) on the care of the elderly disturbed patient.

A modern mental hospital is capable of doing an efficient job in providing a comprehensive psychiatric service for all types of cases because it is no longer forced to take patients that are not strictly in need of psychiatric care. Like the general hospital, its efficiency and morale is grossly lowered if it becomes silted up with elderly people who ought to be in either part-III accommodation or in efficient geriatric units run by competent consultant geriatricians. Before the new legislation the mental hospital was forced to accept on a three-day order many patients whose mental state was secondary to physical illness. Once these patients gained admission to a mental hospital it was often extraordinarily difficult, if not impossible, to arrange their discharge or transfer, and so the real needs in terms of accommodation for the elderly were masked by the overcrowding of mental hospitals. Now that the mental hospital can and should refuse this indiscriminate admission of the elderly the real situation is becoming apparent to all, especially to the overburdened general practitioner. The remedy is simple and could be reached by a more realistic policy. Priority should now be given to an urgent and substantial increase in local-authority part-III accommodation and to the provision of efficient geriatric units by regional hospital boards. Desirable though the provision of acute psychiatric units may be as part of general hospitals, they are far less important at this stage than the provision of adequate accommodation for the elderly. If this accommodation is not provided, then our expected psychiatric units may also, like our mental hospitals and general hospitals become silted up with patients who do not require their services.

A good mental hospital, relieved of the burden of caring for the elderly who are not in need of psychiatric treatment, can do all that a psychiatric unit in a general hospital can do and perhaps better. Enthusiasm for the building of psychiatric units is inspired by the feeling that once psychiatry is integrated with general medicine then the stigma will be removed. This is an unproven hypothesis and can well await testing until the much more urgent needs of the elderly have been met.

The Towers Hospital,

Humberstone,
Leicester.

H. B. KIDD.

\section{TRANYLCYPROMINE}

SIR,-May I add another to the number of cases recently described where the administration of tranylcypromine has been accompanied by neurological disturbances?

A woman, aged 60 , with a long history of manic depressive illness, was admitted to hospital in a state of depression accompanied by retardation. Tranylcypromine was prescribed, because our impression was that this drug is often effective comparatively quickly in such cases. Three hours after receiving her second dose (i.e., after a total of $20 \mathrm{mg}$.) and while she was sitting in a chair, her left foot began to twitch violently; minutes later, this involved her left arm; and on examination, some 10 minutes from the onset, it was found that her left arm and left leg were jerking violently, her head and eyes were turned to the left, the blood-pressure was $180 / 120 \mathrm{~mm}$. $\mathrm{Hg}$, and a Babinski response was elicited in the left foot. Her breathing became stertorous, and death seemed possible. Paraldehyde was given intramuscularly, and gradually the jerking ceased and her breathing became normal. Three hours later she was quite conscious and able to speak, although in a low voice. The picture by then was of a left hemiparesis. After 48 hours, she seemed completely normal.

It was known that her blood-pressure had varied over the last few years from as low as $150 / 80$ to $210 / 140$, this last figure being obtained whilst she was in a manic state. She was having no drugs of any sort for at least four weeks before admission, and tranylcypromine only was given before the incident described occurred.

Warlingham Park Hospital, Warlingham,

WILLIAM MCQUAKER.

SIR,-I completely agree with Dr. Macdonald (Feb. 2). My experiences with this drug in the form of 'Parstelin' (tranylcypromine Sulphate $10 \mathrm{mg}$. and trifluoperazine $1 \mathrm{mg}$.) have been previously recorded. ${ }^{1}$

This report referred to 500 patients, but the number treated to date exceeds 1000 . Headache occurred in approximately $3 \%$ of the cases, but was severe in 1 patient only. This lady was being treated for migraine and was referred to an eminent consultant neurologist, who concluded that the symptoms were within the limits of that illness and did not think that the drug was the cause.

As reference has been made to general practitioners in this correspondence, I sent out a questionnaire to 50 doctors, selected at random from the local medical list. The replies indicated that 5 had not used the drug at all, but that the remainder had treated a total of over 1000 patients. Few had experienced side-effects, and no case of severe occipital headache had been encountered.

In my opinion parstelin is a most effective antidepressant. It acts rapidly, it is reliable, and in the dosage which I have used (i.e., rarely exceeding one tablet morning and noon) it has few side-effects of any clinical importance. It produces a good response in most types of depression, and it is necessary to use E.C.T. only in a small minority of cases.

St. James's Hospital,

Portsmouth,

W. Liddell Milligan.

\section{I.ACTIC ACIDOSIS}

SIR,-We were interested in your leading article of Jan. 19. An explanation of this interesting phenomenon should also consider the possibility of decreased hepatic removal of lactate.

As the equilibrium of the lactate-dehydrogenase reaction lies well towards the formation of lactate and D.P.N., a high D.P.N./D.P.N.H. ratio is necessary for hepatic removal of lactate to occur. Calculations based on the redox potential ${ }^{2}$ and substrate ratios ${ }^{3}$ both agree that the D.P.N./D.P.N.H. ratio in the cytoplasm must be about a thousand times higher than can be observed by direct measurement of the tissue content of pyridine nucleotides. The maintenance of such a high D.P.N. D.P.N.H. ratio is a requisite for lactate removal by the liver, being lowered, as anticipated, in experimental ischæmia. ${ }^{4}$ Any lesion which would interfere with the entry of reducing equivalents into the mitochondria, or their oxidation by the electron transport chain, would be expected to result in a similar lowering of the cytoplasmic D.P.N./D.P.N.H. ratio.

Experimental verification of this suggestion does not at present, seem possible in man, and must await a suitable experimental model in animals.

Department of Internal Medicine, Section of Gastroenterology,

University of Michigan Medical School, Ann Arbor, Michigan, U.S.A.

KeIth S. Henley.

1. Milligan, W. L. Med. Proc. S. Afr. 1962, 8, 237.

2. Beucher, Th., Klingenberg, M. Angez. Chem. 1958. 70, 552

2. Beucher, Th., Klingenberg, M. Angew. Chem. 1958. 70, $195 ., 332,18$.

4. Hohorst, H. J., Kreutz, F. H., Reim, M. Biochem. Biophys. Res. Com $1961,4,159$. 